\title{
Ruminal and post-ruminal digestion of starch from 2 types of concentrates in the young calf during and after weaning
}

\author{
JP Lallès ${ }^{1}, \mathrm{~S}$ Pochet ${ }^{2}, \mathrm{C}$ Poncet ${ }^{3}$ \\ ' INRA, laboratoire du Jeune Ruminant, 65, rue de Saint-Brieuc, 35042 Rennes Cedex; \\ 2 INRA, Station expérimentale laitière, 39800 Poligny; \\ 3 INRA, unité de la Dynamique de la digestion, 63122 Saint-Genès-Champanelle, France
}

\begin{abstract}
Abrupt weaning of young calves from milk to concentrate led to rapid development of rumen and starch digestion (Leibholz, 1978). We report data obtained using progressive weaning, a more common rearing method in France.

Eleven duodenal and ileal-fistulated Friesian calves were weaned by reducing and then suppressing starch-free skim milk by wk 7 and 10 respectively (Lallès and Poncet, 1990). Solid diets fed from wk 7 were based on hay $(20 \%)$ and concentrate $(80 \%)$. The latter contained either pea $(71 \%, A)$ or soyabean meal $(29 \%, B)$ mixed with maize starch (19 and $59 \%)$ in order to obtain similar starch contents $(53$ and $57 \%$ on a DM basis). Starch digestion in the rumen, small and large intestine was studied during (wk 9-10) and twice (wk 15-16 and 19-20) after weaning, as described earlier (Lallès and Poncet, 1990).
\end{abstract}

Starch was almost totally digested by 3 wk after commencement of dry feeding (table
I). It was mainly degraded in the rumen, as observed by Leibholz (1978). However more starch from diet $A$ containing pea reached the duodenum, presumably because of its different botanical origin and/or processing. Starch apparent digestibility in the small intestine was similar for both diets (0.77). It was, however, lower than that of barley (Leibholz , 1978). Limited amounts of starch were digested in the large intestine.

In conlusion, progressive weaning of calves did not consistently modify the pattern of starch digestion which is mainly located in the rumen. Starch from the peacontaining diet appeared to be less degraded in the rumen than maize starch.

Lallès JP, Poncet C (1990) Livest Prod Sci 24, 129-142

Leibholz J (1978) Aust J Agric Res 29, 12931299

Table I. Starch intake, apparent digestibility in total gut and contribution (\%) of main compartments in the calf

\begin{tabular}{|c|c|c|c|c|c|c|c|}
\hline \multirow[b]{2}{*}{$\begin{array}{l}\text { Concentrate type } \\
\text { (observations) }\end{array}$} & \multirow{2}{*}{\multicolumn{2}{|c|}{$9-10$ (weaning) }} & \multicolumn{4}{|c|}{ Calf's age (wk) } & \multirow[b]{2}{*}{$\begin{array}{l}\text { Residual } \\
\text { SD }\end{array}$} \\
\hline & & & $A(6)$ & $\begin{array}{l}16 \\
B(5)\end{array}$ & $\begin{array}{c}19 \\
A(6)\end{array}$ & -20 & \\
\hline Starch intake $(g / d)^{a}$ & 333 & 356 & 601 & 682 & 987 & 1015 & 15.3 \\
\hline Apparent digestibility (\%) & 99.4 & 99.5 & 99.4 & 99.5 & 99.1 & 99.4 & 0.06 \\
\hline Rumen ${ }^{b}$ & 90.9 & 91.6 & 88.3 & 94.3 & 89.6 & 93.3 & 0.49 \\
\hline Small intestine $b$ & 7.7 & 7.4 & 8.6 & 4.0 & 8.9 & 6.1 & 0.43 \\
\hline Large intestine $a, b$ & 1.4 & 1.0 & 3.1 & 1.7 & 1.6 & 0.5 & 0.17 \\
\hline
\end{tabular}

Significant effects of call age a and concentrate type ${ }^{b} ;(P<0.05)$. 